\title{
Proposta de Diretrizes Sanitárias para Avaliação do Prazo de Validade de Saneantes com Ação Antimicrobiana de Uso na Assistência À Saúde
}

\author{
PROPOSAL OF SANITARY LINES OF DIRECTION FOR EVALUATION OF \\ THE SHELF LIFE OF HEALTH ASSISTANCE BIOCIDES
}

\author{
Ubiracir Fernandes Lima Filho(*) \\ Claudia Valeria Campos de Souza(**) \\ Tereza Cristina dos Santos ${ }^{(* * *)}$ \\ Lúcio Mendes Cabral (*****)
}

\section{RESUMO}

Até a finalização deste estudo, não existia no Brasil uma legislação no seguimento de produtos saneantes que disponibilizasse um guia cientificamente embasado para realização de estudos de estabilidade. 0 objetivo deste trabalho consiste na análise das legislações para registro de produtos saneantes de uso em assistência à saúde no Brasil, comparando seus diferentes critérios de estudo com legislações internacionais. Como resultado desta análise, propõem-se um guia para garantir a eficácia e a segurança ao longo do prazo de validade definido para estes produtos. Verifica-se que as legislações internacionais estudadas apresentam critérios

(*) Doutor em Vigilância Sanitária pelo Instituto Nacional de Controle de Qualidade em Saúde, Fundação Oswaldo Cruz (INCQS/Fiocruz); Mestre em Química, Universidade Federal do Rio de Janeiro (UFRJ); Graduado em Química, Universidade Federal Fluminense (UFF). Brasilia/DF, Brasil. E-mail: <ubiracir@yahoo.com.br>.

${ }^{(* *}$ Doutora em Química de Produtos Naturais, UFRJ; Mestre em Química de Produtos Naturais, UFRJ; Graduada em Farmácia, UFRJ. Rio de Janeiro/RJ, Brasil. E-mail:<c_souza@far.fiocruz.br>. ${ }^{(* *)}$ Doutora em Química de Produtos Naturais, UFRJ e Universittá Cattolica del Sacro Cuore, Roma, Itália; Mestre em Química de Produtos Naturais, UFRJ; Graduada em Farmácia, Universidade de Lisboa, Lisboa, Portugal. Pesquisadora da Fiocruz. Rio de Janeiro/RJ, Brasil. E-mail: $<$ t_santos@far.fiocruz.br>.

$\left.{ }^{* * \star \star}\right)$ PhD em Tecnologia Farmacêutica na Universitá La Sapienza, Roma, Itália; Doutor em Química de Produtos Naturais, UFRJ; Mestre em Química Medicinal, UFRJ; Graduado em Farmácia Industrial, UFRJ. Professor associado da UFRJ e Vice-diretor da Faculdade de Farmácia, UFRJ. Rio de Janeiro/ RJ, Brasil. E-mail: <lmcabral@ pharma.ufrj.br>.

Texto recebido em 19.10.09. Revisado em 03.08.10. Nova revisão em 03.11.10. Aprovado em 10.11.10. 
mais rígidos, tais como (i) a avaliação das especificações de qualidade e segurança ao longo de todo o prazo de validade proposto; (ii) a avaliação do comportamento da embalagem e informações da rotulagem; (iii) o uso de uma metodologia de análise validada; (iv) e quando aplicável um estudo que simule as variações do produto nas condições de uso (ex.: diluições ou ativação para uso). Após análise crítica destas legislações, chega-se à proposta de um guia adequado às realidades do setor produtivo brasileiro, de forma a se regulamentar este procedimento como parte integrante do processo administrativo de registro sanitário nas rotinas da Agencia Nacional de Vigilância Sanitária - Brasil (ANVISA).

\section{Palavras-chave:}

Desinfetantes; Esterilizantes Químicos; Registro de Produtos Saneantes; Prazo de Validade; Vigilância Sanitária.

\section{ABSTRACT}

There is no current law in Brazil with a scientifically based guide for performing stability studies for sanitary products. The goal of this work is to analyze the legislation for registering sanitary products of health assistance used in Brazil while comparing its study criteria with the ones of international legislation. The international legislation presented a more rigid criteria for (i) proposed shelf life quality and safety specification evaluation; (ii) label information and packing behavior evaluation; (iii) use of validated analysis methodology; and (iv) studies to simulate the product variations in the conditions of use when applicable (i.e. dilutions or activation for use). In order to regulate this procedure as part of the Agencia Nacional de Vigilância Sanitária - Brazil (ANVISA) routine for sanitary registry administrative process, a guide suitable for the reality of the brazilian productive sector is proposed as a result, after critically analyzing this legislation.

\section{Keywords:}

Chemical Sterilizers; Disinfectants; Sanitary Product Registry; Sanitary Surveillance; Shelf Life.

\section{INTRODUÇÃO}

Os produtos saneantes foram definidos pela Lei n. 6.360, de 23 de setembro de 1976 como substâncias ou preparações destinadas à higieniza- 
ção, desinfecção ou desinfestação domiciliar, em ambientes coletivos e/ou públicos, em lugares de uso comum e no tratamento de água, compreendendo os inseticidas, raticidas, desinfetantes e detergentes. Com a evolução tecnológica, melhor avaliação dos riscos sanitários e necessidade de tratamento específico para as diferentes categorias de saneantes, desenvolveram-se legislações que atualmente os apresentam em novas categorias e classificam em razão do local, destino e/ou restrições de uso, e finalidade de emprego.

Conforme publicado na Resolução RDC n. 184, de 22 de outubro de 2001, essa nova classificação agrupa os saneantes em quatro grandes categorias quanto à finalidade de emprego, que são os produtos para limpeza geral e afins; produtos com ação antimicrobiana; produtos biológicos à base de microorganismos vivos; e os produtos desinfestantes. Ao abordar os processos de registro, a RDC n. 184/01 contempla a organização em dois grupos distintos de acordo com características observadas na avaliação de risco, os produtos de Risco I, de menor risco associado aos componentes de sua formulação e à destinação de uso, e produtos de Risco II, que apresentam maior risco associado aos seus componentes e têm como fator de maior relevância durante o processo de registro, a comprovação da eficácia a que se propõem.

Entre outras informações técnicas previstas na RDC n. 184/01, são contemplados as indicações da data de fabricação e do prazo de validade atribuído aos produtos, que garanta justamente a eficácia enquanto estiverem disponíveis para uso.

\section{PRAZO DE VALIDADE}

O prazo de validade para os saneantes é descrito internacionalmente como o tempo em que o produto se mantém apropriado para uso em todo período de validade(1). No Brasil, o Decreto n. 3.961/01, define como tempo durante o qual um produto poderá ser usado. Além disto, tem determinação prevista na Portaria n. 327/97, que orienta as "Boas Práticas de Fabricação e Controle" dos saneantes, ao solicitar que sejam efetuados testes de estabilidade antes da comercialização. Já nas legislações específicas das diferentes categorias de produtos saneantes, o prazo de validade tem determinação descrita de forma distinta.

A Portaria n. 89/94, exige para as categorias de alvejantes e água sanitária a apresentação de relatório técnico de estudo de estabilidade. Para

(1) CROPLIFE International. Guidelines for Specifying the Shelf Life of Plant Protection Products. Technical Monograph n. 17. Disponível em: <http://www.gcpf.org/library/documents/ Technical\%20Monographs/Technical\%20Monograph\%20№17\%20-\%20May\%201993.pdf>. Acesso em: 27 set. 2006. 
os alvejantes e produtos para jardinagem amadora, regulamentados pela Resolução RDC n. 326/05 e pela Portaria n. 322/97 respectivamente, e ainda, para os desinfetantes regulamentados pela Portaria n. 15/88 e pela RDC $n$. 14/07, solicita-se apresentação de dados que comprovem estabilidade do produto pelo prazo de validade pretendido. Já para os produtos biológicos, a Resolução RDC n. 179/06, orienta indicação do prazo de validade proposto para comercialização.

Ao avaliar estas legislações, observa-se que apenas para produtos categorizados como alvejantes e água sanitária, é solicitado como parte da documentação de registro, relatório técnico descrevendo a metodologia seguida para determinação do prazo de validade. Para as demais categorias, há exigência da simples declaração do tempo determinado como prazo de validade, sem apresentação de qualquer procedimento técnico que o fundamente, ou é solicitada apresentação de dados para comprovação da estabilidade, onde estes dados, quando gerados a partir de um estudo de estabilidade inadequado(2)(3), indicam prazo de validade que pode não representar aquele em que os produtos mantêm suas características originais de eficácia e segurança.

Neste contexto, ao observar mais especificamente os produtos categorizados como desinfetantes para assistência à saúde e os esterilizantes, nota-se que uma perda na eficácia eleva o risco de ocorrência de infecções hospitalares, uma vez que a ação desejada para tais categorias de produtos depende de diversas variáveis, tais como, forma de aplicação bem como da natureza e, fundamentalmente, da concentração da substância ativa presente na formulação(4)(5). Ressalta-se que essas formulações são misturas de substâncias químicas, soluções, e que reagirão espontaneamente levando ao possível consumo da substância ativa e, consequentemente, à redução da eficácia. Torna-se evidente então a importância de um estudo de estabilidade criterioso para determinação do prazo de validade para registro de saneantes, e tratando-se de antimicrobianos, esse estudo representa abordagem importante no combate de possível resistência de microrganismos em ambientes hospitalares associados à ineficiência dessa categoria(6)(7)(8).

(2) OECD.Guideline for Testing of Chemicals, Screening Test for Thermal Stability and Stability in Air. Guideline, n. 113, 1981.

(3) CIPAC (Colaborative International Pesticide Analytical Council). Accelerated Storage Procedure, MT46.3, 2000.

(4) RUTALA, William A.; WEBER, David J.; HEALTHCARE INFECTION CONTROL PRACTICES ADVISORY COMMITTEE. Draft Guideline for Disinfection and Sterilization in Healthcare Facilities. February of 2002. Disponível em: <http://www.premierinc.com/all/safety/resources/guidelines/ downloads/12_draft_dsguide_accessible_02.pdf>. Acesso em: 03 mar. 2004.

(5) BLOCK, S. S. Disinfection, sterilization, and preservation. 5. ed. Pennsylvania: Williams \& Wilkins, 2000. p. 31-44.

(6) RUSSEL, A. D.; MCDONNELL, G.; Concentraton: a major factor in studying biocidal action. Journal of Hospital Infection, v. 44, p. 1-3, 2000.

(7) RUSSEL, A. D. Bacterial adaptation and resistance to antiseptics, disinfectants and preservatives is not a new phenomenon. Journal of Hospital Infection, v. 57, p. 97-104, 2004.

(8) RUSSEI, A. D. et al. Possible link between bacterial resistance and use of antibiotic and biocides. Antimicrobial Agents and Chemotherapy, v. 21, p. 51, Aug 1998. 


\section{Objetivo}

Este trabalho teve como objetivo a análise comparativa das diretrizes nacionais com legislações disponibilizadas pelos países pertencentes ao grupo Mercosul, Estados Unidos e pela União Europeia, para o registro de produtos saneantes com ação antimicrobiana, desinfetantes de uso em assistência à saúde e esterilizantes, e propor diretrizes para desenvolvimento de um guia, com intuito de fornecer suporte às regulamentações existentes e estabelecer procedimentos para estudos de estabilidade que eleve a confiabilidade nos prazos de validade atribuídos a estes produtos, minimizando o risco sanitário associado ao uso sem a eficácia desejada.

\section{Metodologia}

Foram analisadas as legislações utilizadas para registro de saneantes no Brasil e no Mercosul por meio das resoluções disponibilizadas pela

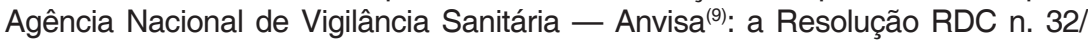
02; a Resolução MERCOSUL/GMC/RES n. 50/06 e a Resolução RDC n. 14/ $07^{(10)(11)(12)}$, e complementado pelo Guia para Estudos de Estabilidade de Medicamentos publicado pela Resolução RE n. 01/05. ${ }^{(13)}$

Para registro nos Estados Unidos, foi analisado o guia disponibilizado pelo FDA, "Guidance for Industry and FDA Reviewers [510(k)]"(14); e para União Europeia foram analisados os documentos: "Directive n. 98/8/EC concerning the placing of biocidal products on the market" ${ }^{15)}$, complementado pelo guia

(9) SANEANTES. Legislação específica da área por assunto. Disponível em: <http:// www.anvisa.gov.br/e-legis/saneantes>. Acesso em: 19 jan. 2004.

(10) RESOLUÇÃO RDC n. 32, de 05 de fevereiro de 2002. Laboratórios que façam parte da Rede Brasileira de Laboratórios Analíticos de Saúde (REBLAS) da Gerência-Geral de Laboratórios em Saúde Pública (GGLAS), da Agência Nacional de Vigilância Sanitária - ANVISA. DOU — Diário Oficial da União, 07 fev. 2002. Disponível em: <http://e-legis.bvs.br/leisref/public/showAct.php?id=1671>. Acesso em: 04 nov. 2004.

(11) MERCOSUL. Regulamento técnico Mercosul para produtos com ação antimicrobiana. Disponível em: <http://www.mercosur.int/msweb/Normas/normas_web/Resoluciones/PT/RES\%20050006_PT_A\%C7AO\%20ANTIMIC.pdf>. Acesso em: 15 out. 2006.

(12) RESOLUÇÃO RDC n. 14 de 28 de fevereiro de 2007. Aprova o Regulamento Técnico para Produtos Saneantes com Ação Antimicrobiana harmonizado no âmbito do Mercosul pela Resolução GMC n. 50/06, que consta em anexo à presente Resolução. Disponível em: <http://elegis.anvisa.gov.br/leisref/public/showAct.php?id=25959>. Acesso em: 03 jan. 2007.

(13) RESOLUÇÃO RE n. 01, de 29 de julho de 2005b. Determina a publicação do Guia para a Realização de Estudos de Estabilidade de Medicamentos. DOU - Diário Oficial da União; Poder Executivo, de 11 de agosto de 2005b. Disponível em: <http://e-legis.anvisa.gov.br/leisref/public/ showAct.php?id=18109>. Acesso em: 25 ago. 2005.

(14) FDA (Food and Drug Administration). Guidance for Industry and FDA Reviewers Content and Format of Premarket Notification [510(k)] Submissions for Liquid Chemical Sterilants/ High Level Disinfectants. Disponível em: <http://www.fda.gov/cdrh/ode/397.html\#_Toc472478075>. Acesso em: 05 nov. 2004.

(15) DIRECTIVE 98/8/EC of the European Parliament and of the Council. Concerning the placing of biocidal products on the market. Official Journal of the European Communities, L 123: 1-63, 1998. 
da "Colaborative International Pesticide Analytical Council - CIPAC", organização não governamental e sem fins lucrativos que promove a harmonização de metodologias analíticas para avaliação da qualidade de formulações de pesticidas, e o uso de suas metodologias é requerido por autoridades de registro da União Europeia; e o guia "Guidance on Storage Stability Data Requirements for Non-agricultural Pesticides Producst" da "Health \& Safety Executive - HSE"(16), órgão responsável pela regulação de quase todos os produtos de riscos à saúde e à segurança na Grã-Bretanha.

Foi também avaliado, uma vez que este seria o modelo adotado pela Anvisa para registro de saneantes no Brasil, o procedimento "Screening Test for Thermal Stability and Stability in Air - Accelerad storage test", disponibilizado pela OECD, "Organization for Economic Co-operation and Development", organização mundial que conta com diversos países-membros, organizações não governamentais, e a sociedade civil.

Buscou-se identificar nestes documentos, pontos considerados de relevância para alcançar segurança e eficácia durante o prazo de validade: definições adotadas para prazo de validade e estudo de estabilidade; tipo de recipiente em que o estudo é conduzido; metodologia analítica indicada para avaliação química; número de lotes recomendados para fins de registro; condições de temperatura e umidade indicadas para o estudo; e frequência em que os testes são realizados.

Uma vez gerado o primeiro documento como proposta para dar origem ao guia, disponibilizou-se para Consulta Pública e discutiu-se os itens com o setor produtivo em reuniões presenciais na ANVISA, para posterior publicação da resolução final.

\section{Resultados}

No Brasil, a Gerência Geral de Laboratórios em Saúde Pública GGLAS, da Anvisa, tornou-se, com a publicação da Resolução RDC n. 32/02, responsável pela habilitação de laboratórios para realização de ensaios analíticos para registros de saneantes, e o método habilitado para determinação do prazo de validade tratava-se do "Screening Test for Thermal Stability and Stability in Air - Accelerad storage test", disponibilizado pela OECD. Nesse teste, uma alíquota da amostra é transferida para um frasco de vidro selado e submetido à temperatura de $54^{\circ} \mathrm{C}$ durante 14 dias. A interpretação dos resultados sugere que a substância seja considerada

(16) HSE (Health and Safety Executive). Guidance on the Storage Stability Data Requirements for Non-agricultural Pesticide Products. Disponível em: <http://hse.gov.uk/hthdir/noframes/ storstabil.pdf>. Acesso em: 05 nov. 2004. 
estável à temperatura ambiente, por um período de 24 meses, quando o ponto de fusão, ou outra propriedade característica, se mantiver constante, ou o conteúdo da substância reduzir não mais do que $5 \%$.

Para os países pertencentes ao bloco do Mercosul, foi proposta a Resolução MERCOSUL/GMC/RES n. 50/06 para registro de produtos com ação antimicrobiana internalizada pela RDC n. 14/07. Esta resolução não apresenta um guia para estudos de estabilidade, é contemplado apenas que seja atribuído um prazo de validade avaliado por dados de estabilidade.

A União Europeia disponibilizou em 1998 a Diretiva n. 98/8/EC, diretriz orientadora dos produtos biocidas, que harmoniza as regras para registro desses produtos. Esse guia preconiza que sejam realizados estudos de estabilidade, e avaliados os efeitos da luz, temperatura e da umidade nas características técnicas do produto e sua reatividade frente ao material de embalagem adotado, porém, não contempla as variáveis que foram selecionadas neste trabalho para análise.

O guia disponibilizado pela HSE apresenta uma série de conceitos técnicos com objetivo de amplificar requerimentos básicos acerca dos dados químicos para a estabilidade durante a estocagem dos produtos formulados. Esses dados são utilizados diretamente na avaliação do perigo associado ao uso durante o prazo de validade, como a perda de eficácia causada pela queda no teor da substância ativa e, consequentemente, o aumento do perigo em razão da formação de novas substâncias químicas com toxicidade elevada. Adicionalmente, destaca a importância na avaliação física das embalagens, bem como as informações técnicas das rotulagens, que devem manter-se legíveis até o final do prazo de validade.

É descrito nesse guia que os dados provenientes de um estudo acelerado podem fornecer importantes indicações acerca da estabilidade dos produtos, todavia, deve ser observado que mesmo com resultados satisfatórios em laboratório, os produtos podem apresentar resultados insatisfatórios em campo. Deste modo, o teste de estabilidade acelerado suportará apenas uma aprovação provisória, e um estudo em temperatura ambiente deverá ser apresentado para aprovação definitiva.

A metodologia analítica empregada em cada teste deve ser validada e seguir um protocolo de Boas Práticas de Laboratório - BPL, como por exemplo a Diretiva da Comunidade Europeia n. 87/18/EEC ${ }^{(17)}$.

O protocolo de estudo deve contemplar uma série de informações acerca do estudo de estabilidade conduzido, tipo do estudo (acelerado e/ou de longa duração); nome do produto; embalagem utilizada; inspeções visuais,

(17) OECD Principles of Good Laboratory Practice. Legislative basis Directive 87/18/EEC, Directive 88/320/EEC. Disponível em: http://pharmacos.eudra.org/F2/eudralex/vol-7/A/7AG4a.pdf>. Acesso em: 05 nov. 2004. 
incluindo inspeções no interior das embalagens com o intuito de verificar sinais de corrosão favorecida por características quimicamente agressivas da formulação; temperatura empregada e frequência de testes (para o teste acelerado $54^{\circ} \mathrm{C}$ e 14 dias, ou quando o produto apresentar acentuada instabilidade pode-se alternativamente as condições de $50^{\circ} \mathrm{C}$ e 28 dias, $45^{\circ} \mathrm{C}$ e 42 dias, $40^{\circ} \mathrm{C}$ e 56 dias ou $35^{\circ} \mathrm{C}$ e 84 dias ou $30^{\circ} \mathrm{C}$ e 126 dias, e para o estudo de longa duração $20^{\circ} \mathrm{C}, 25^{\circ} \mathrm{C}$ ou $30^{\circ} \mathrm{C}$ dependendo da área em que o produto será utilizado, com intervalos de 3, 6 e 24 meses para qualquer uma das 3 temperaturas adotadas); número de lotes testados (admite-se apresentação de apenas um lote); método analítico empregado na avaliação das substâncias ativas; número do lote; tabelas e figuras quando apropriados; cálculos utilizados na avaliação do teor da substância ativa; e resultados e conclusões.

Já nos Estados Unidos, o FDA disponibiliza um documento desenvolvido com orientações para o registro, especificamente de produtos desinfetantes de alto nível e esterilizantes químicos, o guia [510 (k)].

No item dedicado ao tema estabilidade, verifica-se algumas particularidades da categoria dos produtos abordados. Uma vez que muitos produtos são diluídos ou no caso dos esterilizantes, necessitam ativação prévia ao uso, observa-se solicitação de estudo da estabilidade destas novas soluções. São previstas duas etapas para registro, uma que comprove o prazo de validade do produto ainda lacrado, e outra que comprove a validade após abertura do frasco. Deve ser também avaliada a estabilidade do produto para cada tipo de embalagem proposta para comercialização, estabelecendo sua compatibilidade com a formulação. Quanto à frequência dos testes, para estudo de estabilidade de longa duração são preconizadas análises a cada 3 meses no primeiro ano, após 6 meses, no segundo ano e, anualmente, até o prazo de validade proposto. Em relação ao estudo acelerado, no guia [510 (k)], não há indicação de periodicidade intermediária de amostragens para sua condução.

Para representar a variabilidade dos lotes produzidos, contemplou-se a utilização de 3 lotes distintos no estudo, a caracterização de qualquer produto de degradação formado, e a indicação, no seu protocolo, da metodologia analítica empregada. 


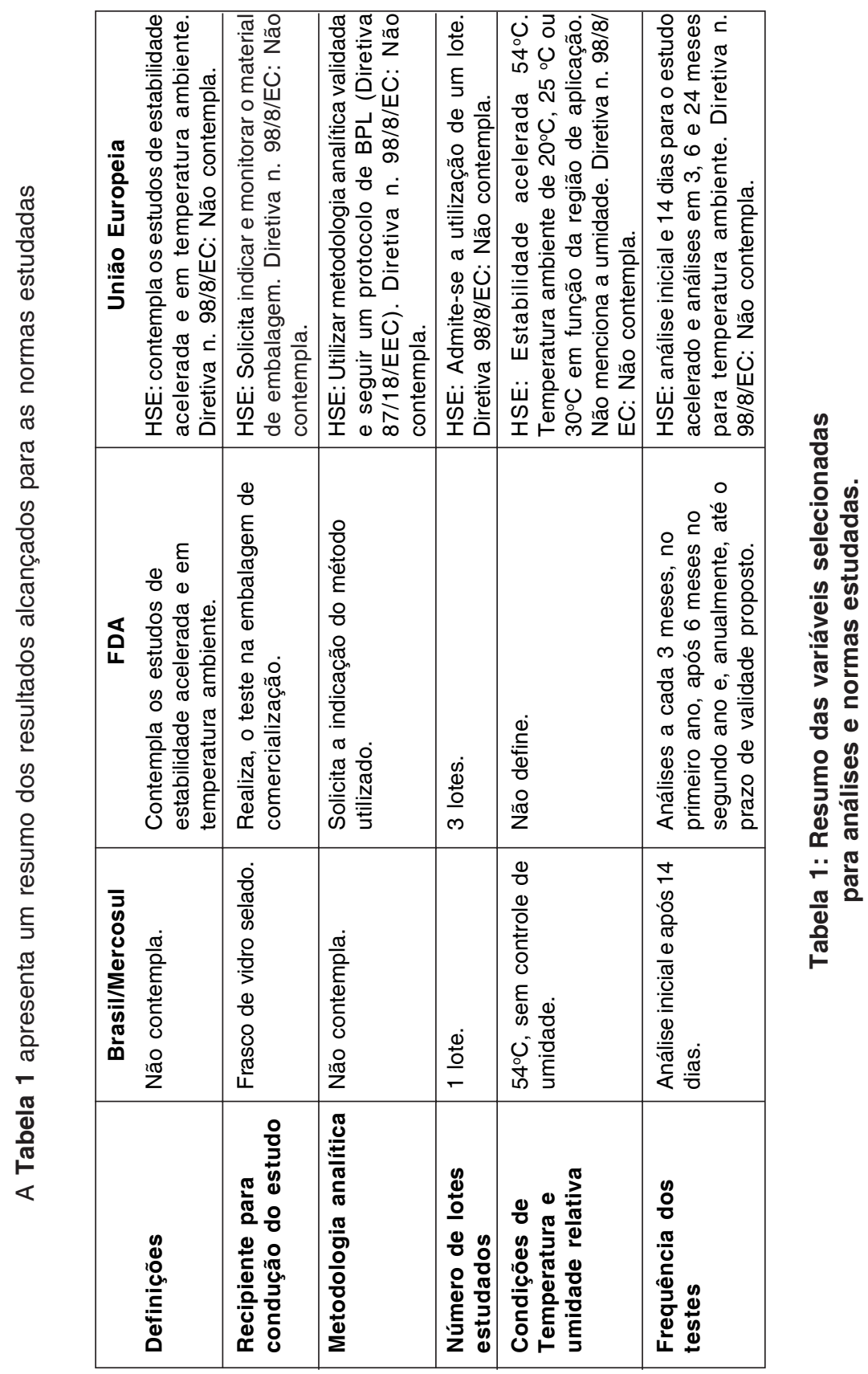




\section{Discussão: proposta de harmonização da legislação}

A análise comparativa das legislações revelou pontos críticos, que são distintos em cada documento.

A ausência de definições quanto aos tipos de estudo, acelerado e de longa duração, abre margem para interpretações errôneas acerca do objetivo. Esse fato é verificado no estudo habilitado no Brasil, onde é previsto apenas o teste acelerado, permitindo que esse seja suficiente para determinação do prazo de validade. Para o grupo do Mercosul, não há indicação de nenhuma metodologia. Os demais documentos estudados, por revelar que o teste acelerado permite apenas a determinação do prazo de validade provisório, já contemplam o estudo em tempo real, ou estudo de longa duração.

Outro fator relevante trata-se da realização do estudo, utilizando amostra na embalagem original, procedimento que permite avaliar interações da formulação com as paredes internas da embalagem, e a capacidade da rotulagem em manter informações técnicas indeléveis.

Um grande avanço observado em alguns documentos internacionais foi determinar o uso de metodologias analíticas adequadas e validadas, e contemplar a avaliação dos produtos de degradação.

O ponto considerado de maior teor crítico é a determinação do prazo de validade de soluções esterilizantes após sua manipulação para uso. Recomenda-se, inclusive como parte de protocolos de serviços de saúde ${ }^{(18)}$, a transferência para recipientes diversos. A questão torna-se evidente quando se observa que, por mecanismo de ação, estes produtos saneantes dependem do teor das substâncias ativas e que teoricamente este teor será reduzido sensivelmente quando expostos à ambientes externos, a embalagem original e quando em contato com novos materiais, os quais não foram testados quanto à compatibilidade química.

De posse destes dados, chegou-se à proposta de diretrizes para desenvolvimento de um guia para os estudos de estabilidade, diante das características do setor produtivo brasileiro. Este documento foi apresentado à Gerência Geral de Saneantes - GGSAN, gerência responsável pelo registro de saneantes na ANVISA, e disponibilizado primeiramente como Consulta Pública, CP n. 16 ${ }^{(19)}$ e, posteriormente, publicado como Resolução RE n. 3169, direcionada pelos seguintes aspectos técnico-sanitários.

Englobou-se os conceitos dispostos nas legislações avaliadas prioritariamente, sendo conceituados termos utilizados na norma e que

(18) Associação Paulista de Estudos e Controle de Infecção Hospitalar. Esterilização de Artigos em Unidades de Saúde. São Paulo. APECIH; 1998.

(19) ANVISA. Consulta Pública n. 16, de 15 de março de 2006. DOU de 17.03.2006. Disponível em: <http://www4.anvisa.gov.br/base/visadoc/CP/CP[14158-1-0].PDF>. Acesso em: 20 mar. 2006. 
cobrem, em um primeiro momento, as demandas técnicas do setor produtivo e da Anvisa, demonstradas durante as reuniões técnicas realizadas.

O estudo de estabilidade acelerada permite projetar um prazo de validade que deve ser confirmado através de um estudo de estabilidade de longa duração. ${ }^{(20)}$

Confirmou-se a necessidade de avaliar as especificações pertinentes ao estudo de estabilidade durante todo o prazo de validade proposto, e que o estudo de estabilidade acelerado isolado não é capaz de determinar com segurança um prazo de validade definitivo.

Fica estabelecido que o prazo de validade embasado no estudo de estabilidade acelerado é de no máximo 24 (vinte e quatro) meses quando nenhum parâmetro exceder os limites especificados para a formulação. ${ }^{(21)}$

Seguiu-se o procedimento atualmente adotado de estudos de estabilidade para produtos saneantes e medicamentos. Este procedimento permite à empresa fabricante solicitar registro para comercialização de seus produtos em curto período de tempo após ter desenvolvido uma formulação. É baseado nos fundamentos da cinética química, que estabelece uma relação entre a cinética de reação e deteminada temperatura.

O fabricante dará continuidade aos estudos de longa duração até atingir o prazo de validade proposto, e os resultados obtidos devem ser apresentados no momento da primeira revalidação do registro, ou quando exigidos pela Autoridade Sanitária Competente. (22)

Uma vez avaliado o comportamento do produto mediante realização do estudo de estabilidade de longa duração, e verificado que os resultados obtidos no estudo acelerado foram reproduzidos, a empresa terá posse de um documento que confirmará o prazo de validade proposto ou revelará a necessidade de alteração deste.

Ressalta-se que dois procedimentos podem ser adotados pela empresa ao final do estudo de longa duração. No caso de validação dos resultados obtidos pelo estudo acelerado, a empresa poderá confirmar o prazo de validade de 24 meses e continuar os estudos de longa duração com o intuito de estender este prazo de validade. Este procedimento deverá ser efetivado, por iniciativa da empresa, apenas no momento da revalidação do registro, momento em que a empresa já protocolizará uma série de informações e, a partir desta norma, incluirá os resultados definitivos do estudo de estabilidade.

(20) BRASIL. Resolução n. 3169, de 22 de setembro de 2006. Disponível em: <http://e-legis.anvisa.gov.br/ leisref/public/showAct.php?id=24039>. Acesso em: 27 set. 2006.

(21) BRASIL. Resolução n. 3169, de 22 de setembro de 2006.

(22) BRASIL. Resolução n. 3169, de 22 de setembro de 2006. 
Ainda com resultados que corroborem os estudos acelerados, a empresa poderá dar continuidade ao estudo de longa duração e mantendo-se os resultados na faixa de especificação, a empresa poderá pleitear extensão do prazo de validade.

No ato da solicitação do pleito de modificação de fórmula do produto, deve ser apresentado o teste de estabilidade acelerada, e, no momento da próxima revalidação, o estudo de longa duração, desde que atingido o prazo de validade proposto para a nova fórmula. ${ }^{(23)}$

Apesar das legislações para registro de produtos saneantes contemplarem o pleito de alteração de formulação, mantendo-se o mesmo número de registro, serão solicitados novos estudos de estabilidade para comprovar o prazo de validade, seguindo a coerência aos testes de eficácia e toxicológicos que já são solicitados.

Para os produtos registrados que estejam em comercialização e que já tenham sido alteradas suas formulações, a empresa fabricante fica responsável pela continuidade da realização do estudo de longa duração até o prazo de validade do referido produto, ficando a cargo da Autoridade Sanitária Competente a necessidade da apresentação dos mesmos. ${ }^{(24)}$

Caso uma empresa tenha interesse em alterar a formulação de um produto antes de completar os 24 meses contemplados como prazo de validade provisório, deverá dar continuidade aos seus estudos de longa duração, uma vez que há possibilidade de encontrar amostras deste produto em comercialização ou em posse do consumidor, e que estaria ainda sob responsabilidade do fabricante.

Os resultados dos estudos de longa duração podem embasar pedido de revisão do prazo de validade proposto e eventuais desvios encontrados durante esses estudos devem ser analisados e justificados, bem como informados imediatamente à Autoridade Sanitária Competente para providências cabíveis. ${ }^{(25)}$

Existe a possibilidade de a empresa solicitar a manutenção, redução ou extensão do prazo de validade provisório, de acordo com os resultados obtidos pelo estudo de longa duração. Confirmou-se a necessidade de haver uma avaliação crítica quanto aos resultados obtidos durante o estudo. Estas avaliações devem ser discutidas, registradas e anexadas ao relatório do estudo que fará parte da documentação para registro ou suas alterações.

(23) BRASIL. Resolução n. 3169, de 22 de setembro de 2006.

(24) BRASIL. Resolução n. 3169, de 22 de setembro de 2006.

(25) BRASIL. Resolução n. 3169, de 22 de setembro de 2006. 
O estudo de estabilidade deve ser executado com o produto em sua embalagem primária original, ou em outra com a mesma composição química e em escala. ${ }^{(26)}$

Em sintonia com o disposto nos documentos disponibilizados pelo HSE e pelo FDA, o tipo e a natureza do material de construção da embalagem têm influência direta na estabilidade das formulações, e portanto, devem fazer parte do estudo.

Para produtos que apresentem componentes elou embalagens comprovadamente sensíveis às temperaturas preconizadas para o estudo de estabilidade acelerada, serão aceitos estudos de estabilidade de longa duração de 6 (seis) ou 12 (doze) meses que projetariam, respectivamente, 12 (doze) ou 24 (vinte e quatro) meses de prazo de validade provisório. ${ }^{(27)}$

Em um primeiro momento, objetivou-se contemplar formulações termossensíveis pela natureza de suas substâncias ativas, com a possibilidade de iniciar o seu processo de comercialização mediante aprovação da documentação de registro que contenha um estudo de estabilidade já iniciado. Após algumas discussões com o setor produtivo contemplou-se também formulações em embalagens comprovadamente instáveis em temperaturas elevadas, tais como os aerossóis.

O estudo de estabilidade, de responsabilidade do detentor do registro, deve contemplar avaliações físicas, químicas, físico-químicas e microbiológicas, quando for o caso, utilizando-se metodologia validada quanto à repetibilidade, à reprodutibilidade e à linearidade na faixa de especificação. ${ }^{(28)}$

Seguindo o critério de qualidade adotado pelo HSE, exigiu-se para métodos analíticos desenvolvidos, que sejam realizados procedimentos mínimos de validação, uma vez que amostras provenientes de estudos de estabilidade estão sujeitas a apresentar produtos de degradação, potenciais interferentes nos métodos analíticos usuais, acarretando em resultados equivocados principalmente quanto à determinação do teor das substâncias ativas.

Para fins de registro ou modificação de fórmula: no mínimo um lote ou lote piloto/experimental.

Para fins de registro de produtos esterilizantes ou modificação de fórmula: no mínimo 3 (três) lotes ou lotes piloto/experimental.(29)

O procedimento habilitado pela GGLAS não preconiza um número mínimo de lotes a ser estudado. Desta forma, os processos de registro para

(26) BRASIL. Resolução n. 3169, de 22 de setembro de 2006.

(27) BRASIL. Resolução n. 3169, de 22 de setembro de 2006.

(28) BRASIL. Resolução n. 3169, de 22 de setembro de 2006.

(29) BRASIL. Resolução n. 3169, de 22 de setembro de 2006. 
comercialização contam com o resultado proveniente do estudo de apenas 1 lote, para representar a homogeneidade do processo produtivo de todos os demais lotes fabricados, enquanto o registro estiver válido na GGSAN.

Este item gerou ampla discussão com representantes das empresas durante o desenvolvimento deste trabalho. A justificativa apresentada baseou-se nos parâmetro de custos, que seriam elevados para empresas de pequeno porte, em maioria no setor produtivo brasileiro.

Alertou-se nestas discussões que o número de 3 lotes seria o mínimo possível para se alcançar um resultado estatístico, e que já se adota este procedimento para estudo de estabilidade de produtos farmacêuticos, inclusive limitando tamanho dos lotes a 1 lote piloto com capacidade de $10 \%$ do lote industrial, e mais 2 lotes com um número mínimo de unidades, que dependerá da forma técnica produzida.

Desta forma, adotou-se nesta primeira etapa ao se trabalhar neste regulamento, a possibilidade de estudo de apenas 1 lote, com a projeção de em futuro próximo, reavaliar também este item no processo de revisão desta norma, e para a categoria de esterilizantes, por critérios de risco associado à destinação de uso, adotou-se a exigência de no mínimo 3 lotes para comprovação do prazo de validade.

A cada dois anos o detentor do registro ou o fabricante deve realizar análise para fins de acompanhamento de uma amostra de retenção ao final do prazo de validade, de pelo menos um lote de cada produto comercializado. ${ }^{(30)}$

Buscou-se neste item minimizar as perdas estatísticas ocasionadas ao se realizar o estudo de estabilidade, utilizando apenas 1 lote em lugar de 3 lotes, adaptando-se o procedimento adotado pelo setor farmacêutico denominado Estudo de Estabilidade de Acompanhamento, estudo que prevê uma análise por ano até o final do prazo de validade proposto, de lotes que são produzidos pela empresa após a concessão do registro.

Para este teste, a empresa deverá seguir o seguinte plano de amostragem:

a) Um lote anual, para produção acima de 15 lotes/ano;

b) Um lote a cada 2 anos, produção abaixo ou igual de 15 lotes/ano;

c) Para produtos com diferentes concentrações e formulações proporcionais, poderá ser utilizado como critério de escolha, aquele que apresentar o maior número de lotes produzidos ao ano.(31)

Para produtos saneantes, em lugar da análise anual prevista no Estudo de Estabilidade de Acompanhamento, optou-se por solicitar uma análise ao

(30) BRASIL. Resolução n. 3169, de 22 de setembro de 2006.

(31) BRASIL. Resolução RE n. 01, de 29 de julho de 2005. Disponível em: <http://e-legis.anvisa.gov.br/ leisref/public/showAct.php?id=18109>. Acesso em: 25 ago. 2006. 
final do prazo de validade dos lotes estudados, e seguir a mesma estratégia de possibilitar ao setor produtivo adaptação gradativa à nova realidade, portanto, prevendo a introdução da avaliação anual para uma revisão desta norma.

Cabe ressaltar que este procedimento busca corroborar também os resultados da validação do processo produtivo, no tocante aos parâmetros de estabilidade, já contemplando variações nas condições climáticas, desvios nas macroestruturas das formulações e inclusive variações nas especificações dos insumos utilizados.

Essa análise deve contemplar todos os testes descritos na especificação de cada produto, ficando a cargo da Autoridade Sanitária Competente a necessidade da apresentação dos mesmos. ${ }^{(32)}$

Neste caso, vislumbrou-se que tanto inspetores quanto responsáveis pela avaliação dos documentos enviados pelas empresas para registros, podem solicitar os resultados destas análises com o intuito de avaliar a uniformidade do processo produtivo.

\subsection{Condições de estocagem das amostras}

O estudo de estabilidade acelerada deve ser realizado a $40^{\circ} \mathrm{C}$ (quarenta graus Celsius) $\pm 2{ }^{\circ} \mathrm{C}$ (mais ou menos dois graus Celsius), ou $50^{\circ} \mathrm{C}$ (cinquenta graus Celsius) $\pm 2{ }^{\circ} \mathrm{C}$ (mais ou menos dois graus Celsius. ${ }^{(33)}$

Inicialmente, buscou-se implementar que a condução dos estudos estivesse sob condições controladas de temperatura e umidade relativa. Após uma série de discussões, optou-se mais uma vez em avançar progressivamente nos critérios para realização dos estudos de estabilidade.

Ressalta-se que no procedimento atualmente adotado para o Brasil e mesmo nos guias internacionais, não é previsto o de controle da umidade relativa, porém, a busca por este controle visa outra importante evolução do procedimento adotado pelo setor farmacêutico que contempla o controle das condições de temperatura e umidade relativa, principalmente, para formulações em base aquosa e embalagens semipermeáveis, situações predominantes nos produtos saneantes.

O estudo de estabilidade de longa duração deve ser realizado na temperatura ambiente. ${ }^{(34)}$

De forma coerente com o item anterior, estabeleceu-se que para estudos de estabilidade de longa duração, as amostras poderiam ser armazenadas

(32) BRASIL. Resolução n. 3169, de 22 de setembro de 2006.

(33) BRASIL. Resolução n. 3169, de 22 de setembro de 2006.

(34) BRASIL. Resolução n. 3169, de 22 de setembro de 2006. 
em ambientes adequados, sem a necessidade de controle de temperatura, porém, com monitoramento constante, com o intuito de se buscar as variações máximas que devem ser permitidas pelo fabricante para as condições de transporte e armazenamento em distribuidoras. Destaca-se que o número de embalagens e o tempo que estas permanecem armazenadas para este estudo é significativamente maior que o previsto para o estudo de estabilidade acelerada. Desta forma, haveria necessidade de um número bem maior de estufas para manutenção destas amostras sob temperatura controlada, ou mesmo salas climatizadas.

\subsection{Frequência dos testes}

\section{Estudos acelerados:}

a) $40^{\circ} \mathrm{C}$ (quarenta graus Celsius) $\pm 2^{\circ} \mathrm{C}$ (mais ou menos dois graus Celsius): Devem ser realizados todos os testes descritos na especificação de cada produto em 0, 3 e 6 meses. ${ }^{(35)}$

Os documentos disponibilizados pelo HSE e pelo FDA apresentam características distintas ao preconizar estudos de estabilidade acelerada. Conforme mencionado no item resultados deste trabalho, o HSE, apesar de preconizar a realização deste estudo, contempla apenas uma análise no inicio do estudo, e outra ao final do tempo estipulado para armazenamento, e o guia $[510(K)]$ do FDA, apesar de mencionar a possibilidade deste estudo, não apresenta qualquer indicação da periodicidade das amostragens.

Desta forma, optou-se por seguir as orientações do guia para realização de estudos de estabilidade de medicamentos, prevendo pelo menos uma avaliação intermediária ao conduzir o estudo acelerado de $40^{\circ} \mathrm{C}$.

b) $50^{\circ} \mathrm{C}$ (cinquenta graus Celsius) $\pm 2^{\circ} \mathrm{C}$ (mais ou menos dois graus Celsius): Devem ser realizados todos os testes descritos na especificação de cada produto em 0 e 3 meses. ${ }^{(36)}$

O mesmo princípio foi utilizado para estudos acelerados de $50 \stackrel{\circ}{\circ}$. Neste caso o guia disponibilizado pelo HSE preconiza a variação do tempo de estudo em função da temperatura adotada, porém, ainda sem orientar quanto à periodicidade de amostragem.

Estudos de longa duração: Devem ser realizados todos os testes descritos na especificação de cada produto em 0, 6 e 12 meses, e anualmente após o primeiro ano até o prazo de validade declarado no registro. ${ }^{(37)}$

(35) BRASIL. Resolução n. 3169, de 22 de setembro de 2006.

(36) BRASIL. Resolução n. 3169, de 22 de setembro de 2006.

(37) BRASIL. Resolução n. 3169, de 22 de setembro de 2006. 
Adotou-se uma frequência de amostragem intermediária entre os documentos disponibilizados pelo HSE e pelo FDA, lembrando que o HSE preconiza amostragens em 3, 6 e 24 meses para realização de análises, e o FDA recomenda a retirada de amostras para análises em 3, 6, 9, 12, 18, 24 e 36 meses.

Ao recordar que o estudo de longa duração tem o objetivo de acompanhar o comportamento do produto durante o prazo de validade proposto, e que a legislação brasileira não contemplava esse estudo, adotou-se novamente a possibilidade de disponibilizar tempo para adaptação e havendo necessidade, reduzir o intervalo de tempo entre as amostragens caso algumas análises revelem resultados muito discrepantes entre duas amostragens consecutivas.

Para produtos que preconizem período de uso após preparação, devem ser realizados todos os testes descritos nas especificações do produto no início e no fim deste período. ${ }^{(38)}$

Cada componente de uma dada formulação pode apresentar comportamentos distintos diante dos estudos de estabilidade de acordo com a natureza química dos demais componentes que fazem parte deste produto. Uma vez que uma nova solução será preparada como produto ativado, torna-se evidente que o prazo de validade deste produto ativado deverá ser distinto daquele determinado para misturas antes da preparação para uso final e, portanto, deverá ser estudado criteriosamente, para então recomendar o tempo em que este produto ativado poderá ser armazenado e em quais condições.

\subsection{Relatório de estabilidade}

O relatório de estabilidade deve apresentar detalhes do estudo, bem como resultados e conclusões. Os resultados devem ser apresentados em tabela (consoante subanexo) e em gráfico.

No relatório, devem constar também:

a) nome do produto ou código;

b) identificação do lote;

c) tamanho do lote;

d) data de fabricação do lote;

e) condições de armazenamento;

f) limites de especificação;

(38) BRASIL. Resolução n. 3169, de 22 de setembro de 2006.

(39) BRASIL. Resolução n. 3169, de 22 de setembro de 2006. 
g) tipo e composição do material de acondicionamento;

h) resultados dos testes;

i) conclusões;

j) data, assinatura do responsável técnico da empresa e número de registro no Conselho Profissional. ${ }^{(39)}$

São dados mínimos que permitirão tanto ao responsável pela avaliação dos dados para registro quanto ao responsável por liberar o estudo na empresa fabricante rastrear e avaliar criticamente os resultados alcançados.

\subsection{Prazo de validade e condições de estocagem recomendadas}

Depois de avaliada a estabilidade, as recomendações de estocagem devem ser indicadas na embalagem do produto.

Informações adicionais como: proteger da luz, manter em lugar seco e outras devem ser incluídas quando necessário.(40)

Alem de reforçar a necessidade de realização de estudos de estabilidade para só então determinar prazo de validade, corrobora também a importância de se proceder estes estudos na sua embalagem original, permitindo a avaliação da estabilidade das informações contidas na rotulagem.

\subsection{Considerações adicionais}

Em caso de produtos que requeiram preparação para uso, deve constar no rótulo o prazo máximo para utilização depois de preparado, baseado em estudos de estabilidade realizados nas condições declaradas para aplicação e armazenamento. ${ }^{(41)}$

Ratificou-se a necessidade de avaliar a validade de soluções preparadas para uso, e que estas informações devem ser geradas a partir de um estudo de estabilidade, e este prazo também deve constar nos dizeres de rotulagem

Condições diferentes das apresentadas neste Regulamento devem ser justificadas tecnicamente e previamente acordadas com a Autoridade Sanitária Competente. ${ }^{(42)}$

Abre-se neste ponto a possibilidade de as empresas desenvolverem suas condições de estudo; porém, este novo desenho deve ser discutido e aprovado antes de sua execução.

(40) BRASIL. Resolução n. 3169, de 22 de setembro de 2006.

(41) BRASIL. Resolução n. 3169, de 22 de setembro de 2006.

(42) BRASIL. Resolução n. 3169, de 22 de setembro de 2006. 


\section{CONSIDERAÇÕES FINAIS}

O desenvolvimento de um estudo criterioso para a determinação do prazo de validade de saneantes, e, sobretudo daqueles destinados ao uso em assistência à saúde, é capaz de elevar a qualidade desta categoria de produtos e, desta forma, contribuir para a saúde da população.

Este guia, baseado em alguns procedimentos adotados pelos EUA, pela Comunidade Europeia, e também alguns conceitos adotados pelo setor farmacêutico brasileiro, apresenta melhorias significantes, principalmente no tocante à necessidade de introdução de um monitoramento analítico dos produtos até o final do prazo de validade, o estudo de estabilidade de longa duração, e da mesma avaliação dos produtos que requeiram ativação previamente ao uso.

\section{REFERÊNCIAS BIBLIOGRÁFICAS}

ANVISA. Consulta Pública n. 16, de 15 de março de 2006. DOU Diário Oficial da União, 17 de março de 2006. Disponível em: <http://www4.anvisa.gov.br/base/visadoc/ CP/CP[14158-1-0].PDF>. Acesso em: 20 mar. 2006.

BLOCK, S. S. Disinfection, sterilization, and preservation. 5. ed. Pennsylvania: Williams \& Wilkins, 2000. p. 31-44.

BRASIL. Decreto n. 3.961 de 10 de outubro de 2001. Altera o Decreto n. 79.094, de 5 de janeiro de 1977, que regulamenta a Lei n. 6.360, de 23 de setembro de 1976. DOU Diário Oficial da União, 17 de março de 2006.. Disponível em: <http://elegis.bvs.br/leisref/public/showAct.php?id=239>. Acesso em: 11 abr. 2004.

Lei n. 6.360, de 23 de setembro de 1976. Dispõe sobre a vigilância sanitária a que ficam sujeitos os medicamentos, as drogas, os insumos farmacêuticos e correlatos, cosméticos, saneantes e outros produtos, e dá outras providências. DOU - Diário Oficial da União, de 24 de setembro de 1976. Disponível em: <http://e-legis.bvs.br/leisref/public/showAct.php?id=178>. Acesso em: 19 mai. 2004.

Portaria n. 15, de 23 de agosto de 1988. Determina que o registro de produtos saneantes domissanitários com finalidade antimicrobiana seja procedido de acordo com as normas regulamentares anexas à presente. DOU - Diário Oficial da União, 05 de setembro de 1988. Disponível em: <http://e-legis.bvs.br/leisref/public/showAct.php?id=286>. Acesso em: 03 mar. 2004.

Portaria n. 89, de 25 de agosto de 1994, Determina que o registro dos Produtos Saneantes Domissanitários "Água sanitária" e "Alvejante" categoria Congênere a Detergente Alvejante e Desinfetante para uso geral 
seja procedido de acordo com as normas regulamentares anexas a presente. DOU - Diário Oficial da União, 26 de agosto de 1994. Disponível em: <http:/ le-legis.bvs.br/leisref/public/showAct.php?id=329>. Acesso em: 11 abr. 2004.

Portaria n. 322 de 25 de julho de 1997. Aprova as Normas Gerais para Produtos para Jardinagem Amadora. DOU — Diário Oficial da União, 08 de agosto de 1997. Disponível em: <http://e-legis.bvs.br/leisref/public/ showAct.php?id=293>. Acesso em: 03 mar. 2004.

Portaria n. 327 de 30 de julho de 1997. Determina a todos os estabelecimentos produtores de Saneantes Domissanitários, o cumprimento das diretrizes estabelecidas pelos Regulamentos Técnicos - Boas Práticas de Fabricação e Controle (BPF e C) e revoga a Portaria n. 58, de 12 de julho de 1995. DOU - Diário Oficial da União, 07 de agosto de 1997. Disponível em: <http://e-legis.bvs.br/leisref/public/search.php>. Acesso em: 03 mar. 2004.

Resolução RDC n. 14, de 28 de fevereiro de 2007. Aprova o Regulamento Técnico para Produtos Saneantes com Ação Antimicrobiana harmonizado no âmbito do Mercosul através da Resolução GMC n. 50/06, que consta em anexo à presente Resolução. Disponível em: <http://elegis.anvisa.gov.br/leisref/public/showAct.php?id=25959>. Acesso em: 03 jan. 2007.

Resolução RDC n. 32, de 05 de fevereiro de 2002. A Gerência Geral de Saneantes (GGSAN) somente aceitará, quando da concessão de notificação e registro de produtos e suas alterações, os testes habilitados, exigidos por legislações específicas, que forem executados por laboratórios que façam parte da Rede Brasileira de Laboratórios Analíticos de Saúde (REBLAS) da Gerência-Geral de Laboratórios em Saúde Pública (GGLAS), da Agência Nacional de Vigilância Sanitária - ANVISA. DOU - Diário Oficial da União, 07 de fevereiro de 2002. Disponível em: <http://e-legis.bvs.br/leisref/ public/showAct.php?id=1671>. Acesso em: 05 nov. 2004.

. Resolução RDC n. 179, de 03 de outubro de 2006. Aprova o Regulamento técnico para Produtos Saneantes à Base de Bactérias harmonizado no âmbito do Mercosul através da Resolução GMC n. 25/06. DOU - Diário Oficial da União, de 04 de outubro de 2006. Disponível em: <http://e-legis.anvisa.gov.br/ leisref/public/showAct.php?id=24164>. Acesso em: 10 nov. 2006.

Resolução RDC n. 184, de 22 de outubro de 2001. Ministério da Saúde. ANVISA. DOU - Diário Oficial da União, 23 de outubro de 2001. Disponível em: <http://e-legis.bvs.br/leisref/public/showAct.php?id=1673>. Acesso em: 19 mai. 2004.

Resolução RDC n. 326, de 09 de novembro de 2005. Aprova o Regulamento técnico para produtos Desinfestantes Domissanitários harmonizado no âmbito do Mercosul através da Resolução GMC n. 49/99, de 14 
de julho de 1995. DOU - Diário Oficial da União, 14 de novembro de 2005. Disponível em: <http://e-legis.anvisa.gov.br/leisref/public/showAct.php?id=19641>. Acesso em: 27 jul. 2005.

. Resolução RE n. 01, de 29 de julho de 2005. Determina a publicação do Guia para a Realização de Estudos de Estabilidade. DOU - Diário Oficial da União; Poder Executivo, 11 de agosto de 2005. Disponível em: <http://elegis.anvisa.gov.br/leisref/public/showAct.php?id=18109>. Acesso em: 25 ago. 2005.

Resolução RE n. 3169, de 22 de setembro de 2006. Aprova o Regulamento desta Resolução, com o objetivo de acrescentar ferramentas à garantia da qualidade, apresentando diretrizes e procedimentos para realização do estudo de estabilidade de produtos saneantes, objetivando, outrossim, gerar informações acerca da segurança e eficácia dos produtos, visando definir prazo de validade consistente. DOU - Diário Oficial da União, 25 de setembro de 2006. Disponível em: <http://e-legis.anvisa.gov.br/leisref/public/ showAct.php?id=24039>. Acesso em: 27 set. 2006.

CIPAC (Colaborative International Pesticide Analytical Council). Accelerated Storage Procedure, MT46.3, 2000.

CROPLIFE International. Guidelines for Specifying the Shelf Life of Plant Protection Products. Technical Monograph n.17. Disponível em: <http:// www.gcpf.org/library/documents/Technical\%20Monographs/ Technical\%20Monograph\%20N.17\%20-\%20May\%201993.pdf>. Acesso em: 27 set. 2006.

DIRECTIVE 98/8/EC of the European Parliament and of the Council. Concerning the placing of biocidal products on the market. Official Journal of the European Communities, L 123: 1-63, 1998.

FDA (Food and Drug Administration). Guidance for Industry and FDA Reviewers Content and Format of Premarket Notification [510(k)] Submissions for Liquid Chemical Sterilants/ High Level Disinfectants. Disponível em: <http:/ /www.fda.gov/cdrh/ode/397.html\#_Toc472478075>. Acesso em: 05 nov. 2004.

HSE (Health and Safety Executive). Guidance on the Storage Stability Data Requirements for Non-agricultural Pesticide Products. Disponível em: <http:/ /hse.gov.uk/hthdir/noframes/storstabil.pdf>. Acesso em: 05 nov. 2004.

MERCOSUL. Regulamento técnico Mercosul para produtos com ação antimicrobiana. Disponível em: <http://www.mercosur.int/msweb/Normas/ normas_web/Resoluciones/PT/RES\%20050-006_PT_A\%C7AO\%20ANTIMIC. pdf>. Acesso em: 15 out. 2006.

OECD Principles of Good Laboratory Practice. Legislative basis Directive $\mathrm{n}$. 87/18/EEC, Directive n. 88/320/EEC. Disponível em: http://pharmacos.eudra.org/ F2/eudralex/vol-7/A/7AG4a.pdf>. Acesso em: 05 nov. 2004. 
OECD. Guideline for Testing of Chemicals, Screening Test for Thermal Stability and Stability in Air. Guideline, n. 113, 1981.

RESOLUÇÃO RDC n. 32, de 05 de fevereiro de 2002. Laboratórios que façam parte da Rede Brasileira de Laboratórios Analíticos de Saúde (REBLAS) da Gerência-Geral de Laboratórios em Saúde Pública (GGLAS), da Agência Nacional de Vigilância Sanitária - ANVISA. DOU - Diário Oficial da União, 07 fevereiro 2002. Disponível em: <http://e-legis.bvs.br/leisref/ public/showAct.php?id=1671>. Acesso em: 04 nov. 2004.

RESOLUÇÃO RDC n. 14, de 28 de fevereiro de 2007. Aprova o Regulamento Técnico para Produtos Saneantes com Ação Antimicrobiana harmonizado no âmbito do Mercosul através da Resolução GMC n. 50/06, que consta em anexo à presente Resolução. Disponível em: <http://e-legis.anvisa.gov.br/ leisref/public/showAct.php?id=25959>. Acesso em: 03 jan. 2007.

RESOLUÇÃO RE n. 01, de 29 de julho de 2005b. Determina a publicação do Guia para a Realização de Estudos de Estabilidade de Medicamentos. DOU - Diário Oficial da União, de 11 de agosto de 2005b. Disponível em: <http:// e-legis. anvisa.gov. br/leisref/public/showAct. php?id=18109>. Acesso em: 25 ago. 2005.

RUSSEL, A. D.; MCDONNELL, G. Concentraton: a major factor in studying biocidal action. Journal of Hospital Infection, v. 44, p. 1-3, 2000.

RUSSEL, A.D. Bacterial adaptation and resistance to antiseptics, disinfectants and preservatives is not a new phenomenon. Journal of Hospital Infection, v. 57, p. 97-104, 2004.

RUSSEI, A. D. et al. Possible link between bacterial resistance and use of antibiotic and biocides. Antimicrobial Agents and Chemotherapy, v. 21, p. 51, Aug 1998.

RUTALA, William A.; WEBER, David J.; HEALTHCARE INFECTION CONTROL PRACTICES ADVISORY COMMITTEE. Draft Guideline for Disinfection and Sterilization in Healthcare Facilities. February of 2002. Disponível em: <http:/ /www.premierinc.com/all/safety/resources/guidelines/downloads/ 12_draft_dsguide_accessible_02.pdf>. Acesso em: 03 mar. 2004.

SANEANTES. Legislação específica da área por assunto. Disponível em: <http://www.anvisa.gov.br/e-legis/saneantes>. Acesso em: 19 jan. 2004.

Agradecimentos:

Ao CNPq pelo suporte financeiro. 